\title{
Educação Corporativa a Distância: uma Revisão Integrativa
} Corporate Distance Education: an Integrative Review

Vinicius Henrique dos Santos Gomes ${ }^{1 *}$

Oilzon Inácio dos Santos Filho ${ }^{1}$

Juliete Lizandra dos Santos

Cavalcante $^{1}$

Gilberto Santana dos Santos Júnior ${ }^{1}$

1 Universidade Federal da Paraíba - Av.

Santa Elisabete, 160, Rio

Tinto, Paraíba - Brasil

*vinicius.henrique@dcx.ufpb.br

\section{Resumo}

A crescente demanda por profissionais com competências específicas levou, de certa forma, as organizações a assumirem responsabilidades com a qualificação de seus funcionários. Para desenvolver habilidades e, assim, melhorar os negócios e reduzir os impactos organizacionais, uma das formas de se promover é por meio da Educação Corporativa. Este trabalho teve como objetivo realizar uma revisão integrativa sobre empresas que investem, promovem e incentivam seus funcionários por meio da Educação Corporativa, apresentando como resultado uma visão geral dos trabalhos.

Palavras-chave: Educação a distância. Educação corporativa. Revisão integrativa.

\section{(c) (i)}

Recebido 05/ 05/ 2020 Aceito 21/ 09/2020

Publicado 22/ 09/ 2020 


\section{Corporate Distance Education: an Integrative Review}

\section{Abstract}

The growing demand for professionals with specific skills, in a way, how to assume responsibilities with the qualification of their employees. Develop skills and, thus, improve business and reduce organizational impacts, one of the ways to promote and through Corporate Education. This work aimed to carry out an integrative review on companies that invest, promote and encourage their employees through Corporate Education, as a result of an overview of the work.

Keywords: Distance Education. Corporative education. Integrative review.

\section{Introdução}

Com a ascensão do mercado econômico e o surgimento de novas empresas com grandes espaços, que renomeiam o berço econômico, incluindo uma geração constante de informações, o mercado de trabalho passou a demandar, significativamente, funcionários que possam estar familiarizados com o aprendizado contínuo, mesmo dentro de uma organização já estabelecida.

Entretanto, ao longo do tempo, as instituições têm ponderado um aumento significativo no acesso de conhecimentos a seus funcionários, corroborando um termo utilizado na literatura como Educação Corporativa (EC), que pode ser compreendida como um processo de formação vinculada aos objetivos estratégicos de uma organização ou instituição (Carvalho, 2015). Refere-se também ao investimento intelectual e cognitivo, promovido por empresas com o propósito de obter um retorno positivo dos seus negócios, bem como vantagens competitivas e expansão da pesquisa, ou seja, agregar valor à empresa.

Silva et al. (2017) aponta que esse termo foi instituído a partir do ano de 1980, momento em que as empresas começaram a perceber a necessidade de implantar o setor de recursos humanos, à disposição de treinamento e qualificação dos funcionários, para executar de forma técnica as demandas de trabalho requeridas naquele tempo. Em seguida, as escolas foram estabelecidas dentro das próprias instituições, adotando um currículo mais centrado, bem como a formação profissional exigida à época.

Mas quais são as vantagens disso? Carvalho (2015) afirma que traz vantagem competitiva, preparação de profissionais mais competentes e preparados para lidar com o mercado contemporâneo; espera-se que suas ações sejam mais assertivas, seu desempenho e resultados superiores. Hoje, a maior parte das ações de EC é realizada dentro das próprias empresas, seja em salas exclusivamente dedicadas a este fim, seja nos espaços disponíveis como salas de reunião ou em espaços para conferências. No entanto, os cursos e aulas ministrados a distância ou na modalidade semipresencial têm- se popularizado e, cada vez mais, os gestores estão dando preferência a esses modelos de ensino.

Com a educação a distância (EAD), é possível que um número maior de colaboradores tenha acesso ao conteúdo ao mesmo tempo, reduzindo o tempo de trabalho na empresa com essa capacitação. Hoje, as ações de EC são direcionadas ao público interno de empresas, colaboradores, de todos os níveis, cargos e diferentes tipos de experiência profissional, mas não se limita a isso.

Dados recentes do censo 2018/2019 da ABED (2019) revelaram um crescimento de 25,4\% no cenário de matrículas no campo de cursos livres corporativos a distância, embora menos do que nos cursos livres não corporativos (36,8\%). Mas a permanência é praticamente a mesma nos dois segmentos: 32,3\% 
nos cursos livres corporativos e 33,3\% nos não corporativos. Em relação ao volume de investimentos em cursos livres corporativos a distância, o índice recuou 7\%, sendo um pouco elevado se comparado aos praticados pelos outros segmentos.

De acordo com outro levantamento, da Escola de Negócios Integração (2019), o investimento médio anual por colaborador das empresas brasileiras em 2019 foi de $\mathrm{R} \$ 652,00$, o que indica uma tendência de queda nos últimos 3 anos: queda de 13\% em relação a 2018. E, pelo segundo ano consecutivo, o volume de treinamentos presenciais vem crescendo, em detrimento do ensino a distância. A hipótese levantada na pesquisa é que as empresas estão reduzindo seus investimentos na construção de projetos de EAD e nas equipes que os gerenciam, pois, por um lado, a EAD requer uma série de investimentos em tecnologia, conteúdo e equipes. Outro destaque é que quanto maior a empresa, mais ela utiliza recursos da EAD (on-line) em seus projetos de treinamento.

A PwC (2008), empresa de consultoria, realizou uma pesquisa em 2007 sobre o futuro do trabalho em 2020, na qual apontava que as empresas da época lidavam com a falta de talento e com a dificuldade de fazer com que as pessoas construíssem força de trabalho eficaz. A pesquisa também imaginou que a gestão de pessoas seria um dos maiores desafios para os negócios e que a área de Recursos Humanos precisaria passar por mudanças fundamentais.

Neste presente trabalho, durante a leitura, será possível refletir sobre as hipóteses da referida pesquisa e inferir, a partir dos resultados de uma revisão integrativa, se essa realidade é emergente. A revisão visou identificar trabalhos que apresentam ferramentas e competências estabelecidas na promoção de educação corporativa e, como resultado, a apresentação de um panorama de trabalhos na área. As quatro seções, contando com esta introdução, serão conduzidas por tópicos, posteriormente à Seção 2 onde é detalhado o protocolo da revisão integrativa. Seção 3, os resultados da revisão são apresentados. A seção 4 apresenta a discussão dos artigos primários selecionados. Por fim, a seção 5 contém as conclusões dos autores.

\section{Método}

A natureza do trabalho é classificada como exploratória e descritiva, uma vez que se destina a levantar e agrupar informações pertinentes sobre educação corporativa no Brasil (Bervian et al. 2002). Em uma revisão integrativa, as pesquisas são sintetizadas, analisadas e investigadas de forma geral, seja em um escopo amplo ou limitado.

Seguindo as orientações de Botelho et al. (2011), esse procedimento é utilizado no campo organizacional e deve ser selecionado quando se deseja realizar "uma análise e síntese do que já foi produzido sobre o tema investigado". O levantamento realizado neste trabalho considerou algumas etapas. Inicialmente, foi definido o protocolo de revisão, que descreve à medida que ocorre o processo de identificação das publicações. Essa descrição contém os objetivos da revisão, as questões de pesquisa, as fontes de busca das publicações, os critérios de seleção dos artigos e o trâmite de seleção dos artigos. Todas essas etapas estão nas subseções a seguir.

\subsection{Objetivos}

O principal objetivo desta pesquisa foi identificar trabalhos sobre empresas que têm investido, promovido e incentivado seus funcionários em Educação Corporativa no Brasil. Foram definidos os seguintes objetivos específicos, com base no objetivo principal: $i$ ) classificar quais setores mais aplicam treinamentos empresariais e priorizam qualificações de mão de obra em sua organização; ii) articular as competências

1 PricewaterhouseCoopers 
individuais e organizacionais a serem desenvolvidas no contexto específico de cada empresa; iii) mapear, dentro da limitação da fonte de busca, as regiões do Brasil que dominaram com publicações relacionadas à Educação Corporativa.

\subsection{Questão de pesquisa}

A próxima etapa da revisão consistiu na seriação de perguntas que direcionaram o levantamento das publicações, sendo importante para extrair dados dos estudos selecionados e atingir os objetivos salientados na seção anterior. O presente estudo foi norteado pelos seguintes questionamentos (QP):

QP1. Quais ferramentas ou plataformas são mais utilizadas para promover o treinamento dos funcionários?

QP2. Que habilidades essas empresas buscaram desenvolver?

QP3. Em que áreas de atividade se dividem as empresas?

QP4. Em quais regiões do país essas empresas estão mais concentradas?

Além das questões de pesquisa mencionadas acima, também foi possível analisar os artigos escolhidos nestes dois pontos: $i$ ) instituições que investem no desenvolvimento de novas ferramentas ou plataformas, e outras que utilizam recursos existentes; ii) tipo de competência atribuída.

\subsection{Estratégias de busca}

O processo de busca utilizado nesta pesquisa baseou-se em duas estratégias: manual (hand searching) e automática. A primeira estratégia procedeu em uma busca manual na base de dados digital do Congresso Internacional de Educação a Distância ABED² (CIAED). Este congresso é o maior da área de Educação a Distância, organiza artigos por categorias e, dentro delas, buscou-se a categoria de EC. Durante a revisão, foram considerados os anais dos últimos quatro anos disponíveis no site (de 2014 a 2018).

No primeiro caso, como a procura foi feita manualmente, não foi necessário definir nenhuma string de pesquisa. Em segundo lugar, uma busca automática na literatura científica foi realizada no banco de dados da BDTD³ ${ }^{3}$ usando os termos (string) da Tabela 1:

Tabela 1: Termos de busca

(Todos os campos: educação a distância) E (Todos os campos: educação corporativa) E (Todos os campos: EAD)

Fonte: Os autores, 2020

\subsection{Seleção dos artigos}

Os artigos primários foram eleitos considerando os critérios de inclusão e exclusão, declarados no Quadro 1. Nesse processo, foram considerados o título, resumo e as palavras-chave. Quando necessário, foi realizada uma busca no artigo para verificar se estava dentro dos critérios.

2 Base de dados ABED.

3 Biblioteca Digital Brasileira de Teses e Dissertações 
Quadro 1: Critérios de seleção dos artigos

\begin{tabular}{|c|c|}
\hline Critérios de inclusão & Critérios de exclusão \\
\hline $\begin{array}{l}\text { - o artigo deve estar em português } \\
\text { - o artigo deve estar disponível integralmente } \\
\text { - o artigo deve tratar somente de educação } \\
\text { corporativa } \\
\text { - o artigo que apresenta uma proposta de } \\
\text { desenvolvimento de material ou ferramenta } \\
\text { - o artigo publicado a partir do ano } 2014 \text { ao } 2018\end{array}$ & $\begin{array}{l}\text { - o artigo que não apresenta uma ferramenta } \\
\text { ou plataforma } \\
\text { - o artigo que não apresenta alguma } \\
\text { competência que se pretende desenvolver } \\
\text { com uma ferramenta } \\
\text { - o artigo que apresenta um relato de experiên- } \\
\text { cia ou pesquisa descritiva } \\
\text { - o artigo que apresenta uma metodologia } \\
\text { de ensino } \\
\text { - o artigo que apresenta estudo de caso }\end{array}$ \\
\hline
\end{tabular}

Fonte: Os autores, 2020

\subsection{Extração dos dados}

Para a amostra inicial resultante das buscas, os achados foram organizados, identificando-os com o indicador $\langle A x\rangle$, onde $x$ representa um número sequencial. Cada trabalho foi lido brevemente para melhor compreender e extrair outras informações de interesse.

Nessa etapa, as informações sobre os trabalhos selecionados na lista final foram extraídas e registradas em um documento ${ }^{4}$ por um grupo de quatro pesquisadores, além de um orientador, com base em um protocolo por ele desenvolvido. O protocolo foi definido de acordo com as questões norteadoras (QP), apresentadas na seção 2.2. A extração de dados compreende a leitura e o armazenamento de dados relevantes dos artigos identificados, que serão descritos em detalhes a seguir.

\section{Resultados}

A primeira fase de apuração consistiu no levantamento dos trabalhos retornados nas buscas, que registraram um total de 90 artigos. Na segunda fase, foram analisadas áreas de atuação, tipo de ferramenta ou plataforma trabalhada, competência a ser desenvolvida, ano de publicação e região. Apenas os selecionados foram atendidos, como definições de inclusão e exclusão, pertencendo a apenas 36 trabaIhos. O tratamento dos dados consistiu apenas nos artigos selecionados. A Tabela 2 abaixo sintetiza os resultados das buscas.

Tabela 2: Síntese dos resultados por motores de busca

\begin{tabular}{c|c|c}
\hline Base de busca & Resultados & Selecionados \\
\hline ABED & 75 & 31 \\
\hline BDTD & 15 & 5 \\
\hline
\end{tabular}

Fonte: Os autores, 2020

Esta revisão integrativa levantou produção no período de 2014 a 2018 . Conforme ilustrado no Gráfico 1, a distribuição de publicações em 2014 e 2015 contemplou com sete artigos e, com menor frequência,

4 Relação detalhada dos artigos selecionados 
2016 e 2018 representaram cinco artigos. O pico é verificado em 2017 ( $n=12)$; mais de 33\% das publicações foram feitas nesse ano.

Gráfico 1: Distribuição de trabalhos por ano

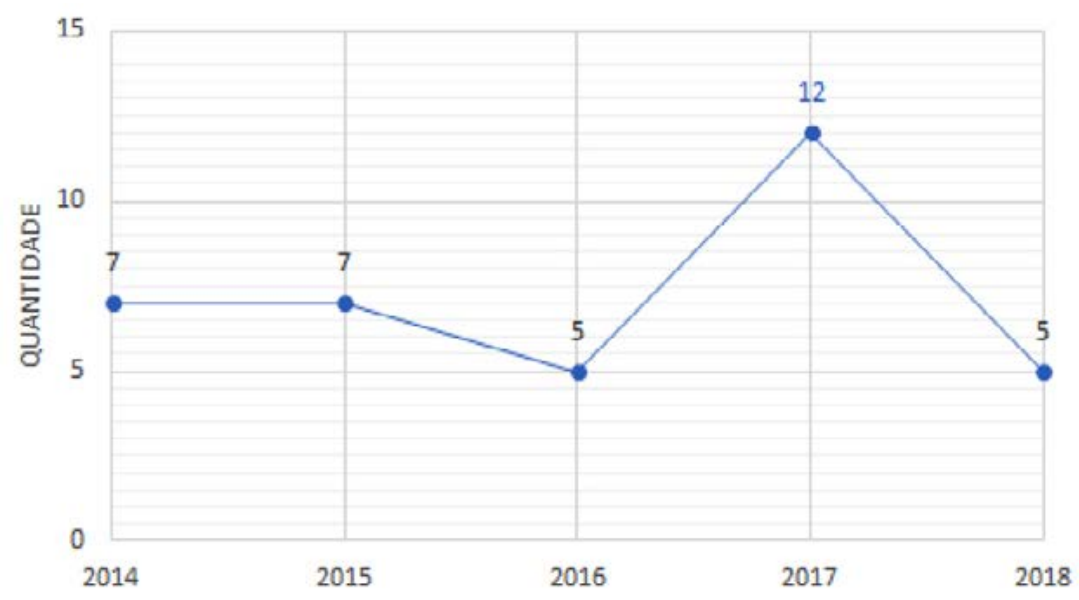

Fonte: Os autores, 2020

A identificação do local de publicação dos estudos foi classificada nas cinco regiões do Brasil. A região que mais investiu em EC foi a Sudeste $(n=17,47 \%)$, abrangendo as áreas do Governo, Educação, Organizações Militares e Financeiras. Foi também a região que investiu em áreas não trabalhadas por outras regiões, como Religioso, Tecnologia e Genérico ${ }^{5}$. Em seguida, o Nordeste $(n=8,22 \%)$ apresentou investimento nos setores Jurídico e Governo. As regiões Centro-Oeste e Sul (ambas n=5, 14\%), atingiram diversificadas áreas do Governo, Finanças e Organizações Militares. Já a região Norte (n=1, 3\%) ficou em última posição, registrando investimentos no setor Jurídico. Esses dados podem ser mais bem observados no Gráfico 2, a seguir.

Gráfico 2: Distribuição das regiões que investem em EC

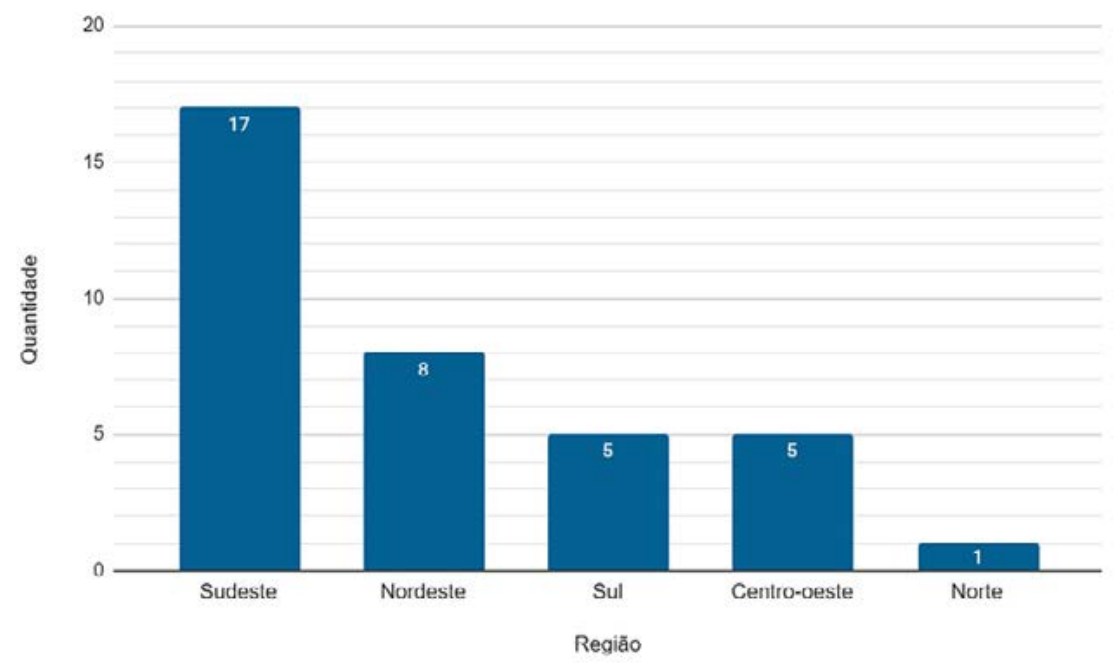

Fonte: Os autores, 2020

5 O campo é considerado genérico, pois envolve mais de um setor corporativo. 


\section{Discussão}

\subsection{Ferramentas e outros meios}

Mediante o processo de análise, foi possível constatar que a ferramenta com maior influência foi o Ambiente Virtual de Aprendizagem (AVA) Moodle, representando um elevado número (39\%) de pesquisas intersetoriais, dominando todos os estudos no setor "Organização Militar" e, em seguida, alguns do setor Jurídico e aplicações também em Financeiro e Governo. Outros trabalhos são apoiados por outros meios, por exemplo, as redes sociais (Facebook, Instagram, WhatsApp, etc.), videoaulas e webconferências, material didático impresso, conteúdo audiovisual e outros. Na área da Educação, esses recursos são mais utilizados, seja com a criação de jogos, seja utilizando ambientes virtuais ou simplesmente com a criação de fóruns, quizzes, videoaulas, etc. Confira esses dados no Quadro 2, a seguir.

Quadro 2: Ferramenta, descrição e relação de trabalhos envolvidos

\begin{tabular}{|c|c|c|}
\hline Ferramenta & Descrição & $\begin{array}{l}\text { Trabalhos } \\
\text { envolvendo a } \\
\text { ferramenta }\end{array}$ \\
\hline Moodle & $\begin{array}{c}\text {-Plataforma Moodle; -Variações do Moodle (EBAula, Programa } \\
\text { EFI, Sistema SAV, Creasol EAD, EAD Banrisul) }\end{array}$ & 15 \\
\hline $\begin{array}{l}\text { Próprias } \\
\text { plataformas }\end{array}$ & $\begin{array}{c}\text {-LMS Saba; -Plataforma da ENAP, baseada no modelo ADDIE; } \\
\text {-Plataforma Digital Sistema de Informações Eletrônicas (SEI); } \\
\text {-AVA da UniCorreios; -Programa de capacitação da UFRPE; } \\
\text {-AVA da Escola Virtual IBGE }\end{array}$ & 6 \\
\hline Redes sociais & $\begin{array}{l}\text {-Comunidades virtuais; } \\
\text { - Mídias sociais (Facebook, Instagram, Whatsapp) }\end{array}$ & 2 \\
\hline MOOC & $\begin{array}{l}\text { MOOC (Massive Open Online Course ou Curso Online Aberto } \\
\text { e Massivo) e SPOC (Small Private Online Course) ou Curso } \\
\text { Online Curto e Privado); }\end{array}$ & 3 \\
\hline Outros meios & $\begin{array}{l}\text {-Mídias (Vídeos, pequenos tutoriais, mascote do curso, criação } \\
\text { de histórias, infográficos, quizzes, Fóruns avaliativos, tutoria, } \\
\text { hiperlinks para materiais extras); -Material didático impresso; } \\
\text {-Videoaulas; -Curso Blended; -Webconferência e materiais de } \\
\text { apoio; -Janelas do Conhecimento, EADicas de Português, EADi- } \\
\text { cas Saúde Financeira e Podcast E-Café; -Conteúdo audiovisual; }\end{array}$ & 7 \\
\hline $\begin{array}{l}\text { Outras } \\
\text { tecnologias }\end{array}$ & $\begin{array}{l}\text {-m-Learning; - Ferramenta de webconferência "Treina TOM"; } \\
\text {-Blog; -Fórum de discussão; }\end{array}$ & 4 \\
\hline
\end{tabular}

Fonte: Os autores, 2020

\subsection{Competências}

Fleury e Fleury (2011) acentuam que competência é um conjunto de conhecimentos, habilidades e atitudes vinculadas à capacidade humana, que conduzem ao desempenho que cada um pode alcançar. Também classifica as competências em três perspectivas: competências técnicas e profissionais (conhecimentos e experiência na ocupação, atividade ou área de atuação); competências sociais (referindo-se a interesses interpessoais, refletindo sobre a capacidade de se comunicar, negociar, flexibilidade, sensibilidade cultural e trabalho); como competências empresariais (relacionadas à compreensão do negócio e sua interação com o mercado, clientes e concorrentes, contexto sociopolítico).

Em relação às competências, notou-se que as empresas estão investindo mais na formação de seus funcionários através da EAD, visando à capacitação dos colaboradores para o trabalho, facilitando a adap- 
tação a métodos e processos, bem como promovendo o desenvolvimento tecnológico e pedagógico dos funcionários, possibilitando a formação na particularidade de cada indivíduo para o sucesso profissional.

Algumas empresas buscam promover competências que se caracterizam como uma habilidade social e não se restringem a competências profissionais e de natureza técnica. Por outro lado, visa a profissionais mais envolvidos no desempenho de suas funções e na interação social; consequentemente, um aprimoramento crescente das empresas investidoras.

\section{3 Áreas de atuação}

Concluiu-se que a EC alcançou empresas de diferentes áreas. Conforme mostra o Gráfico 3, o setor que mais investiu foi Governo ( $(n=9)$, seguido por Jurídico $(n=7)$, Educação $(n=6)$, Financeiro e Organização Militar ( $n=5)$, e as demais áreas contiveram ( $n=1)$ trabalhos. As subseções a seguir detalham cada uma.

Gráfico 3: Distribuição de trabalhos por áreas de atuação

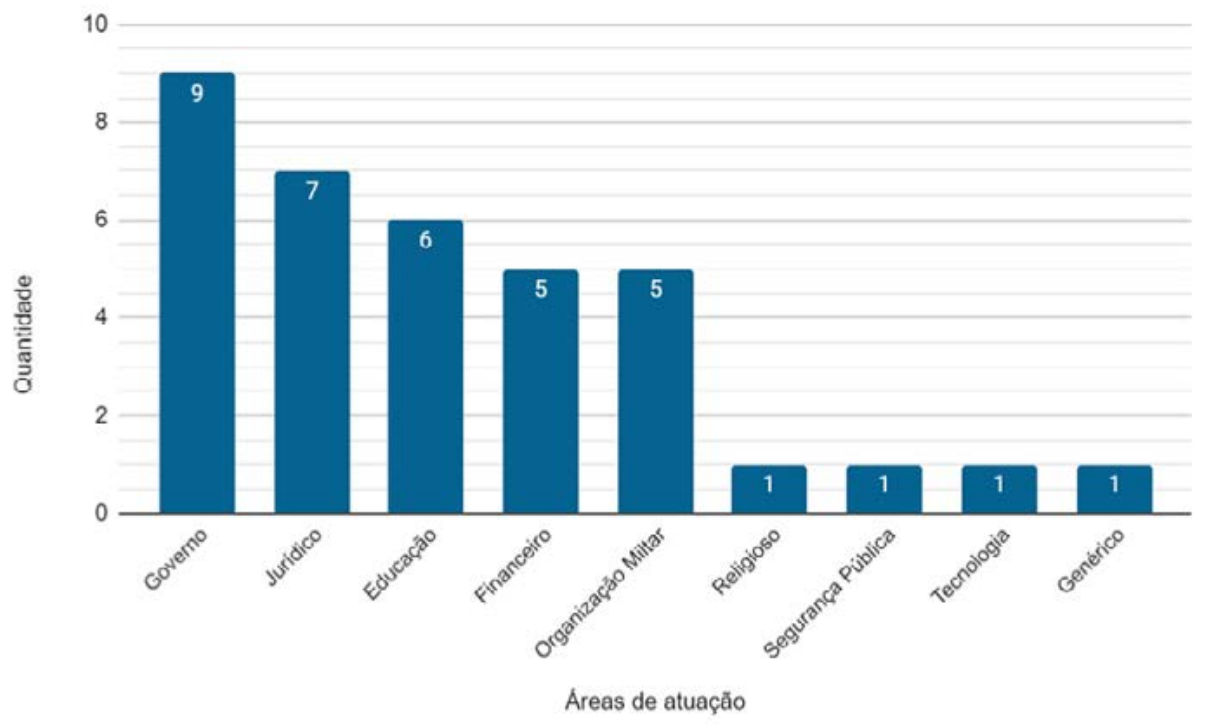

Fonte: Os autores, 2020.

\subsubsection{Educação}

O setor da Educação [A01:A06] representa 16,7\% dos trabalhos, envolvendo subsetores comerciais, como o SESC [A04], apresentando uma pedagogia ativa, dialógica e interativa, capaz de fomentar redes de cooperação solidária e a promoção de ambientes polissêmicos, favorecidos de reflexões sobre problemas emergentes. O SEBRAE [A01], promovendo a cultura da inovação nas Pequenas Empresas. E universidades a distância [A06], oferecendo cursos de extensão.

\subsubsection{Financeiro}

O setor Financeiro [A07:A11] tem um investimento de 13,9\% na EC. Neste grande setor, integram-se as cooperativas de crédito [A09], capacitando colaboradores, aprimorando processos de gestão e rotinas diárias. Bancos estatais [A07], voltados para o negócio, têm como objetivo principal melhorar o atendimento ao cliente. E o Serviço de Proteção ao Crédito - SPC [A08 e A11], para capacitação de entidades sobre os produtos e serviços do SPC Brasil, por meio da divulgação de informações técnicas, comerciais e gerenciais. 


\subsubsection{Governo}

O maior investimento é no setor Governo [A12:A20], com um percentual de $25 \%$ dos trabalhos resultantes, incluindo empresas intersetoriais, como o IBGE [A15 e A20], atendendo as necessidades da instituição, como tempo para treinar, dispersão de pessoas pelo território nacional e contenção de custos. $O$ ENAP [A12], que envolve funções administrativas, desenvolvendo roteiros de produção que serão utilizados na própria plataforma. Os Correios [A17], sistema brasileiro de envio e entrega de correspondências, têm como objetivo promover a educação a distância, engajar os gestores como educadores líderes e estimular o autodesenvolvimento das equipes.

\subsubsection{Jurídico}

Na sequência, o setor Jurídico [A21:A27] tem 19,4\% dos achados; nele predominam os Tribunais Regionais do Trabalho (TRT) de várias regiões do país, exceto o Sul. Em [A21], o objetivo é estimular os alunos a criar estratégia, autonomia, liberdade e autogestão na aprendizagem. Em [A23], a finalidade é aumentar a eficiência das instituições que trabalham com a formação e desenvolvimento profissional de servidores públicos nas três esferas (federal, estadual e municipal) e nos três poderes (executivo, legislativo e judiciário). Por fim, [A25] visa aprimorar magistrados e servidores públicos.

\subsubsection{Organização Militar}

O setor Organização Militar [A28:A32], que quantifica 13,9\% dos artigos selecionados, envolve especificamente atividades para o Exército Brasileiro [A28, A30, A32], com o intuito de capacitar profissionais do exército e facilitar, integrar, compartilhar trabalhos ou informações entre os militares envolvidos na Preparação da Força Terrestre. As escolas de base militar [A29] têm como alvo a construção de um modelo inédito de um jogo RPG de apoio à decisão, denominado Sistema de Apoio à Decisão (SAD-ESAO), a ser utilizado por vários grupos simultaneamente e que contribui para a melhoria do processo de trabalho. Outro campo de atuação encontrado foi a Aeronáutica [A31], que se destaca por desenvolver competências para a formação de profissionais em gestão e fiscalização de contratos administrativos.

\subsubsection{Outras áreas}

Os setores com baixo investimento (2,8\%) foram Segurança Pública [A34], com aplicação na Polícia Rodoviária Federal, apresentando um curso sobre regras de ingresso e permanência no programa Educação Física Institucional (EFI). O setor de Tecnologia [A35] leva proprietários e gestores de empresas de Tecnologia da Informação (TI) a refletirem sobre a formação de seus colaboradores. O setor classificado como Religioso [A33], capacita anciãos a exercerem uma liderança efetiva e significativa, para impactar positivamente a comunidade local. Por fim, o campo Genérico [A36], conduz o estudo sobre a potencialização dos processos de ensino e de aprendizagem em algumas áreas corporativas.

\section{Conclusão}

Este artigo apresenta resultados de uma revisão integrativa, culminando com um panorama de trabaIhos sobre Educação Corporativa a distância. Neste cenário, foram identificadas regiões de investimento, competências, ferramentas ou plataformas utilizadas para promover o conhecimento. Possibilitou destacar alguns pontos sobre as instituições que investem em EC no Brasil, trazendo resultados relevantes para a geração de mais conhecimento nesta área temática. 
A realização desta pesquisa permitiu perceber que a EC favorece de forma definitiva quanto à progressão empresarial, pois favorece o aprimoramento contínuo e elevado como competências, através de novos conhecimentos. Relacionando a aprendizagem aos objetivos estratégicos, têm grandes possibilidades de garantir um processo de desenvolvimento contínuo no seio das organizações, permitindo-lhe reduzir um grande número de obstáculos, implícitos ou explícitos.

Os resultados apontam limitações e potencialidades na produção em investigação, atribuindo um escopo reduzido, a partir de duas bases para a pesquisa. Portanto, vislumbrando trabalhos futuros, pretende-se realizar novos estudos com o propósito de conhecer, sistematizar e contribuir com mais informações sobre Educação Corporativa no Brasil. Além disso, os trabalhos fragmentados podem servir de amostra inicial para uma revisão sistemática específica por área de atuação. E considerando o crescimento das pessoas nas plataformas digitais e mídias sociais, é fundamental que surjam novas formas de promoção do ensino, permitindo refletir sobre a relação entre a tecnologia e a consequente ausência de interação (in absentia) e outras formas de participação.

\section{Referências}

ABED - Associação Brasileira de Educação a Distância (2019). Censo EaD.BR 2018: Relatório analítico da aprendizagem a distância no Brasil. Curitiba: Intersaberes. $1^{\text {a }}$ edição p. 123. Disponível em: http://abed.org.br/arquivos/censo digital ead 2018 portugues.pdf. Acesso em: 05 ago. 2020.

BERVIAN, P. A.; CERVO, A. L.; SILVA, R. d. (2002). Metodologia Científica. São Paulo: Pretence Hall, p. 482-493.

BOTELHO, L. L. R., CUNHA, C. C. de A., \& MACEDO, M. (2011). O Método da Revisão Integrativa nos Estudos Organizacionais. Gestão E Sociedade, 5(11), 121-136. https://doi.org/10.21171/ges.v5i11.1220.

CARVALHO, V. M. (2015). A importância da Educação Corporativa para a vantagem competitiva das organizações. Caderno De Administração, 23(1), 60-67. http://periodicos.uem.br/ojs/index.php/CadAdm/article/view/28451/16140.

FLEURY, M. T. L.; FLEURY, A. C. C. (2011) Estratégias Empresariais e Formação de Competências: Um Quebra-cabeças Caleidoscópico da Indústria Brasileira. 3. Ed. São Paulo: Atlas.

INTEGRAÇÃO - Escola de Negócios (2019). Panorama do Treinamento no Brasil: Indicadores e Tendências em Gestão do T\&D. 14 $4^{\mathrm{a}}$ Ed. Disponível em: https://integracao.com.br/wp-content/uploads/2020/02/pesquisa-panorama-do-treinamento-no-brasil-2019.pdf. Acesso em: 04 ago. 2020.

SILVA, G. J. et al. (2017). Educação corporativa: Uma reflexão sobre a absorção, criação, disseminação e retenção de conhecimentos nas organizações. Rev Espacios. ISSN 0798-1015. Vol. 38, n 20.

PWC - Pricewaterhouse Coopers (2008). Gestão de pessoas no futuro: O futuro do trabalho em 2020. Relatório Técnico. Disponível em: http://www.conhecer.org.br/download/cp/GESTAODEPESSOAS/ leituraanexa4.pdf. Acesso em: 04 ago. 2020. 